\title{
Thermal and Electrical Properties of Irradiated Styrene Butadiene Rubber-Metal Composites
}

\author{
S.E. Gwaily, G.M.Nasr* and M.M. Badawy* \\ National Center for Radiation Research and Technology, \\ Nasr City, P.O.Box 29, Cairo, Egypt. \\ * Phys. Dept., Faculty of Science, Cairo University, Giza, Egypt.
}

The effect of $\gamma$-radiation on both the electrical and thermal properties of styrene butadiene rubber (SBR) loaded with different concentration ratios of copper $(\mathrm{Cu})$ and iron $(\mathrm{Fe})$ fine powder has been studied. The d.c. electrical conductivity $\sigma$ for all loaded SBR composites was highly affected by $\gamma$ radiation dose. The addition of different fillers do not contribute much to the thermal properties of these composites. The filler-filler inter-spacing distance was found to be highly affected by the $\gamma$ - radiation dose, which in turn influences the electrical conductivity of these composites. 


\section{Introduction:}

The majority of polymeric materials are electric insulators in nature[1]. However, they can be rendered conductive by different methods:

(a) Creation of conjugated double bonds in the backbone chain of polymers $[2,3]$.

(b) Introduction of donor-acceptor complex in the polymer matrix [4], and

(c) Adding conductive fillers such as metallic powders and carbon black [5-8].

One of the goals of materials research is to create new materials with physical properties tailored to a particular application and to understand the mechanisms controlling these properties.

Irradiation of different types of rubber was early studied by Tarssova et al [9]. The effect of the polymer composition on radiation induced crosslinking was studied by many workers [10-12].

It is well known that electrical conduction in polymers can be considerably enhanced by irradiation [13]. The increase in conductivity of irradiated polymers may be attributed to the formation of conjugated structures [14]. Also, the irregularity in the polymer chain may give rise to a hopping mechanism that will enhance the conductivity [15].

The present investigation aims to clarify the effect of $\gamma$-radiation on both the electrical and thermal properties of styrene butadiene rubber (SBR) loaded with mixed concentration ratio of $\mathrm{Cu}$ and $\mathrm{Fe}$ metal fine powder. Moreover, the filler-filler interspacing distance is calculated empirically as a function of both $\gamma$ - dose and filler content.

\section{Experimental}

\subsection{Sample preparation}

The styrene butadiene rubber (SBR) and the other conventional additives were mixed with different concentration ratios of $\mathrm{Cu}$ and $\mathrm{Fe}$ powders as shown in Table (1) on a roll mill, under typical industrial mixing conditions.

The investigated rubber specimens were shaped during the vulcanization process (under 78.4 MPa pressure at $160^{\circ} \mathrm{C}$ for $60 \mathrm{~min}$.) into the form of discs of radii $0.75 \mathrm{~cm}$ for the thermal and $0.5 \mathrm{~cm}$ for the electrical measurements and a common thickness of $0.2 \mathrm{~cm}$. 
Table (1): Composition of SBR composite samples with different concentration ratios of $\mathrm{Cu} / \mathrm{Fe}$ fine powder.

\begin{tabular}{|l|c|c|c|c|c|c|}
\hline $\begin{array}{l}\text { Ingredients } \\
\text { (phr) }^{\mathbf{a}}\end{array}$ & S1 & S2 & S3 & S4 & S5 & S6 \\
\hline SBR (1502) & 100 & 100 & 100 & 100 & 100 & 100 \\
\hline Stearic acid & 2 & 2 & 2 & 2 & 2 & 2 \\
\hline Processing oil & 10 & 10 & 10 & 10 & 10 & 10 \\
\hline Fe & 0 & 10 & 30 & 50 & 70 & 90 \\
\hline Cu & 0 & 90 & 70 & 50 & 30 & 10 \\
\hline MBTS $^{\text {b }}$ & 2 & 2 & 2 & 2 & 2 & 2 \\
\hline PBN $^{\mathbf{C}}$ & 1 & 1 & 1 & 1 & 1 & 1 \\
\hline ZnO $^{\text {Sulpher }}$ & 5 & 5 & 5 & 5 & 5 & 5 \\
\hline
\end{tabular}

1) part per hundred parts of rubber by weight

2) dibenthiazyl disulphide

3) pheny $1-\beta$ - naphthylamine

\subsection{Thermal Measurements}

The thermal properties (thermal diffusivity, a, specific heat capacity, $\mathrm{C}_{\mathrm{p}}$, and the thermal conductivity, $\lambda$ ) were measured using the modified flash method technique [16].

The samples were shaped into discs with diameter $1.5 \mathrm{~cm}$ and thickness of about $2 \mathrm{~mm}$. The amplifier used was Yokogawa model 3031 and the $y$-t recorder was Linseis LY 14100-11.

\subsection{Electrical and Irradiation Measurements}

The ammeter-voltmeter method was used for measuring the d.c.electrical conductivity. The electrical conductivity $\sigma$ was calculated by using the following equation:

The essential device in the circuit is a Keithley 485 autoranging picoammeter. The circuit was also interfaced with a computer in order to obtain the I-V characteristics for the samples under investigation. The a.c. conductivity and dielectric constant were obtained by using LCR bridge type Hioki 3531Z, Japan. All samples were thermally aged at $70{ }^{\circ} \mathrm{C}$ for 30 days before irradiation, to ensure their structure stability. A ${ }^{60} \mathrm{Co}$ gamma source model GB150 type B manufactured by the Atomic Energy Agency of Canada and located at the National Center for Radiation Research and Technology, A.E.A. was used for irradiating the samples at a dose rate of $9.23 \mathrm{kGy} / \mathrm{h}$, and a constant temperature $30{ }^{\circ} \mathrm{C}$. 


\section{Results and Discussions:}

\subsection{D.C. Conductivity}

The electrical conductivity for these tested composites was observed to be in the insulating range $\left(10^{-12} \Omega^{-1} \mathrm{~cm}^{-1}\right)$ even on loading with filler. This may be due to either the elastomeric nature of SBR which causes segregation of the metal filler particles after molding [17], or the interfacial effects between metals and polymers. The temperature dependence of conductivity (log $\sigma$ versus $1 / T$ ) for samples containing different metallic fillers ratios is shown in Fig. (1). The distinct feature which is evident from Fig. (1) is that, in general, the conductivity increases with increasing temperature, thus showing a positive coefficient of conductivity (PTCC) all over the investigated temperature range except for the S4 ,S5 and S6 samples with $\mathrm{Cu} / \mathrm{Fe}$ ratios $(50 / 50,30 / 70$ and $10 / 90)$. In these samples anomalous decrease of conductivity with increasing temperature (-ve TCC) takes place at different temperature ranges shifted to higher temperatures with increasing Fe content (330-363 K for S4, 340-374 K for $\mathrm{S} 5$ and 350-375 $\mathrm{K}$ for $\mathrm{S} 6$ ).

Two regions in the curves of Fig. (1) may be considered, region I (up to $345 \mathrm{~K})$, and region II $(\mathrm{T}>363 \mathrm{~K})$. The activation energy $(\Delta \mathrm{U})$ for electrical conductivity has determined from this graph is seen to be in the range of $0.1 \mathrm{eV}-2.5 \mathrm{eV}$ for I and $0.2 \mathrm{eV}-0.76 \mathrm{eV}$ for II. The value of $(\Delta \mathrm{U})$ in each of these regions depends on the filler concentration ratio.

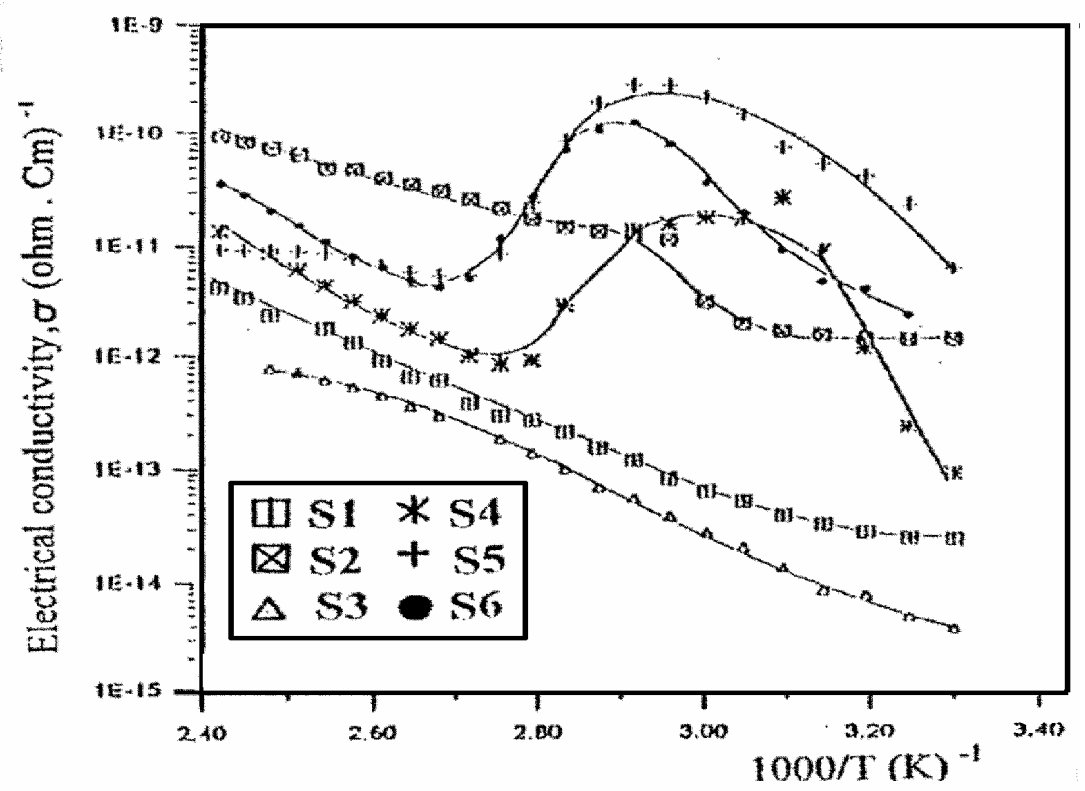

Fig. (1): The temperature dependence of the d.c. electrical conductivity for SBR samples loaded with different metallic filler $(\mathrm{Fe} / \mathrm{Cu})$ ratios. 
The anomalous behaviour of conductivity detected as minima and maxima values $\left(\sigma_{\text {min. }}\right.$ and $\sigma_{\text {max. }}$ ) in Fig.(1) might be due to the competition of two conduction mechanisms (the activated conduction mechanism and the hopping conduction one). The detected PTCC and NTCC for these composites consist with the suggestion that the interfacial phenomena control the temperature dependence of the conductivity behaviour of these composites[17].

\subsection{Radiation Dose Dependence of the Electrical Properties}

An appropriate method to detect different degrees of the filler dispersion in the rubber matrix is based on the measurements of the electrical conductivity of the rubber compound either with dc [18] or ac [19] mode. Figure (2 a-e) represent the dependence of the current density $J$ as $\log J\left(A m p / \mathrm{m}^{2}\right)$ versus the electric field $\mathrm{E}(\mathrm{Volt} / \mathrm{m})$ at room temperature $\left(30^{\circ} \mathrm{C}\right)$ for all samples irradiated with different $\gamma$ - doses. The dependence can readily be fitted to an empirical formula of the form [2]:
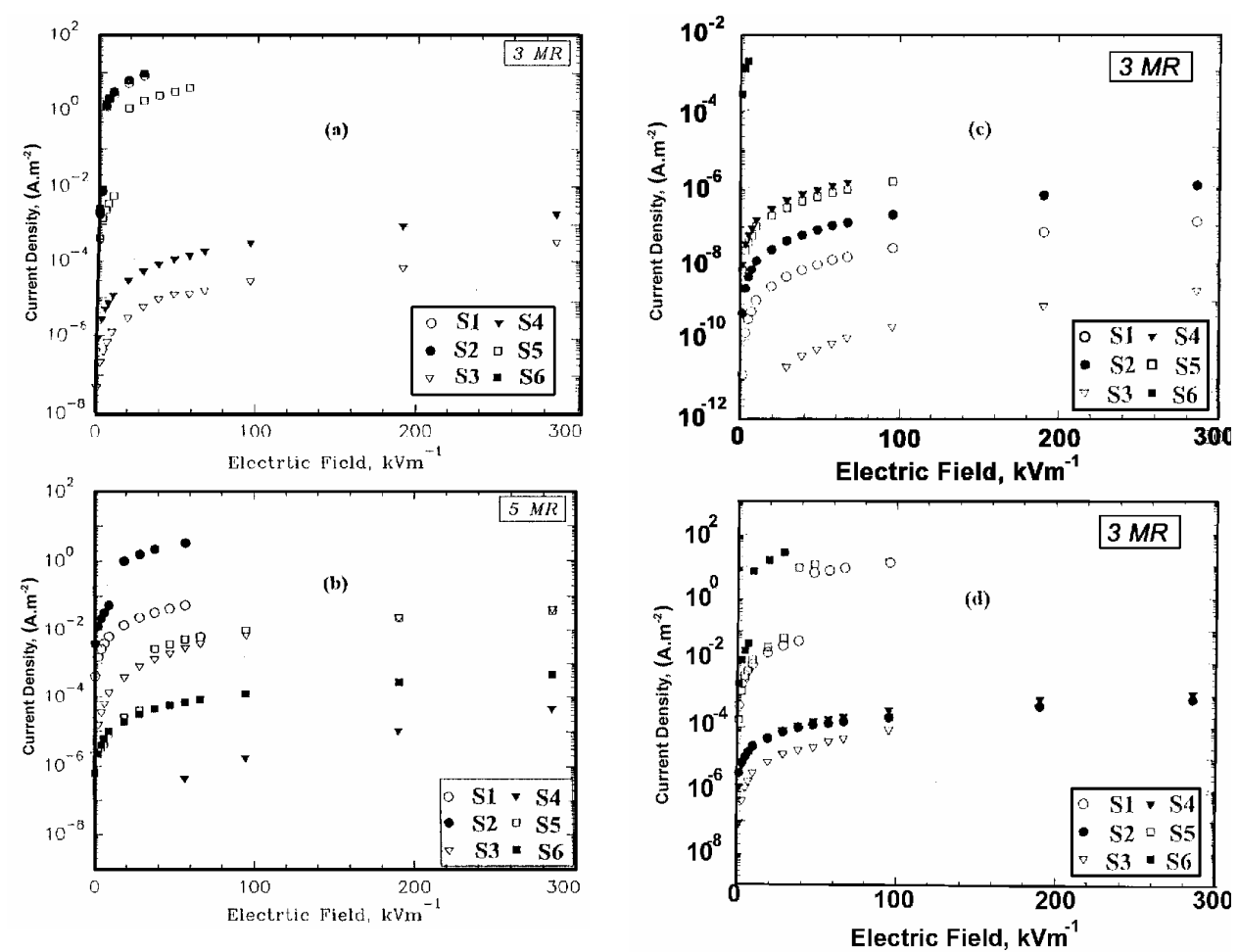

Fig. (2a-e): The current density-electric field characteristics for all samples irradiated with different $\gamma$-doses 


$$
\mathrm{J}=\mathrm{J}_{\mathrm{o}} \sinh (\omega / 2 \mathrm{kT})
$$

where $\mathrm{J}_{0}$ is a fitting parameter that depends on both $\gamma$ - dose and filler content in the SBR matrix , $\omega=\mathrm{deE}, \mathrm{d}$, is the average separation distance between filler particles $(\mathrm{Cu}$ and/or $\mathrm{Fe})$, e is the electronic charge, $\mathrm{k}$ is the Boltzmann constant and $\mathrm{T}(\mathrm{K})$ is the ambient temperature. The estimated values of, $d$, could be obtained (by using the iterative method) from Fig. (2 a-e) and are tabulated in Table (2). The dependence of, $d$, on $\gamma$ - dose is not quite the same for all samples, but an appreciable decrease in, $d$, was detected for most samples owing to the creation of free electrons by $\gamma$ - dose in the filled SBR matrix.

Table (2): The interspacing distacne $d$ between filler particles, and $J_{0}$ for all samples irradiated with different $\gamma$ - radiation doses.

\begin{tabular}{|c|c|c|c|}
\hline Sample & $\boldsymbol{\gamma}$-dose (M rad) & $\mathbf{J}_{\mathbf{0}}\left(\mathbf{A m p . \mathbf { c m } ^ { - 2 }}\right)$ & $\mathbf{d}(\mathbf{n m})$ \\
\hline & 3 & $8.5 \times 10^{-3}$ & \\
S1 & 5 & $9.3 \times 10^{-5}$ & \\
& 10 & $2.5 \times 10^{-6}$ & \\
\hline \multirow{3}{*}{ S2 } & 3 & $8.5 \times 10^{-3}$ & 1000 \\
& 5 & $2 \times 15^{-3}$ & 12 \\
& 10 & $2 \times 10^{-6}$ & 250 \\
\hline \multirow{3}{*}{ S3 } & 3 & $5 \times 10^{-6}$ & 250 \\
& 5 & $10 \times 10^{-6}$ & 50 \\
& 10 & $2 \times 10^{-8}$ & 50 \\
\hline \multirow{3}{*}{ S4 } & 3 & $8 \times 10^{-8}$ & 1450 \\
& 5 & $7 \times 10^{-7}$ & 1000 \\
& 10 & $5 \times 10^{-6}$ & 160 \\
\hline \multirow{3}{*}{ S5 } & 3 & $8 \times 10^{-1}$ & 1760 \\
& 5 & $1 \times 10^{-6}$ & 500 \\
& 10 & $22 \times 10^{-9}$ & 60 \\
\hline \multirow{2}{*}{ S6 } & 3 & $11 \times 10^{-5}$ & 800 \\
& 5 & $1 \times 10^{-6}$ & 8 \\
& 10 & $1.8 \times 10^{-6}$ & 16 \\
\hline
\end{tabular}

In order to determine the charge transport mechanism, $\log \mathrm{J}$ was replotted again versus the square root of the electric field $\mathrm{E}^{1 / 2}$ as shown in Fig.(3).

This relation gave almost a linear behaviour at higher fields with an appreciable deviation from linearity at lower fields. This deviation. may be attributed to the accumulation of space charge at the electrodes [21].This linear variation between $\log \mathrm{J}$ and $\mathrm{E}^{1 / 2}$ suggests a conduction mechanism in which carriers can be released by thermal activation over a Coulombic potential 
barrier that is decreased by the applied electric field [22]. The physical nature of such a potential barrier can be defined in terms of the slope value by one of two basic effects. It can be considered as a transition of electrons over the barrier between cathode and dielectric (Schottky effect). Alternatively, charge carriers can be released due to ionization of impurity centers in the dielectric (Poole- Frenkel effect). The conductivity $\sigma$ is therefore given as;

$$
\sigma=\sigma_{\mathrm{o}} \exp \left(\beta \mathrm{E}^{1 / 2} / \mathrm{KT}\right.
$$

where $\sigma_{\mathrm{o}}$ is the low field conductivity and $\beta$ is a constant denoted as $\beta_{\mathrm{RS}}$ (for Schottkey effect) or $\beta_{\mathrm{PF}}$ (for Poole -Frenkle effect).
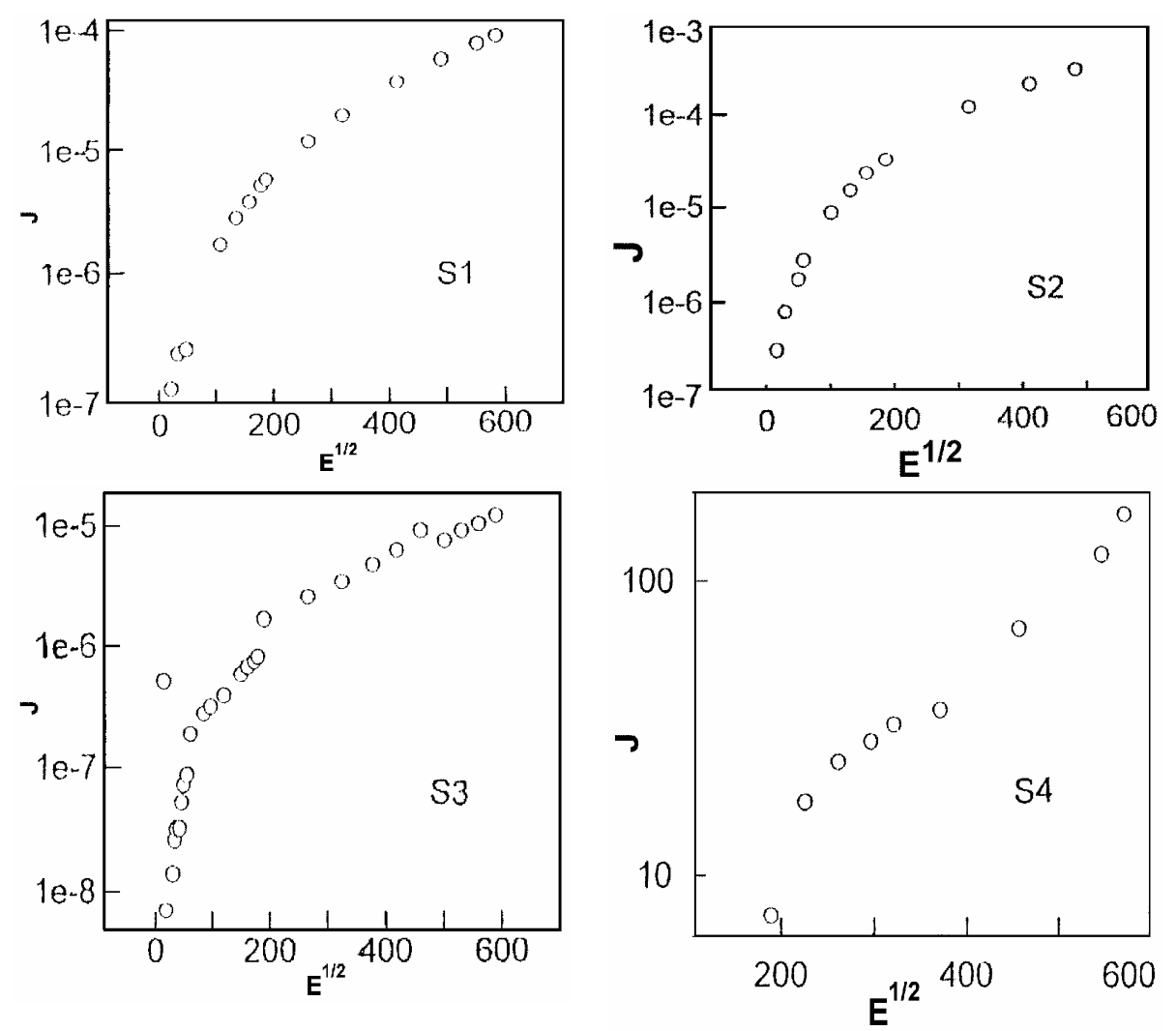

Fig. (3): Variation of $\log \mathrm{J}$ with the square root of the electric field for all samples.

To determine the operating conduction mechanism, the values of $\beta$ for samples with different $\gamma$-doses deduced from the slopes of the plots of $\log \mathrm{J}$ against $\mathrm{E}^{1 / 2}$ (Fig .4 for S4 as an example) are compared with the theoretical value the deduced from: 


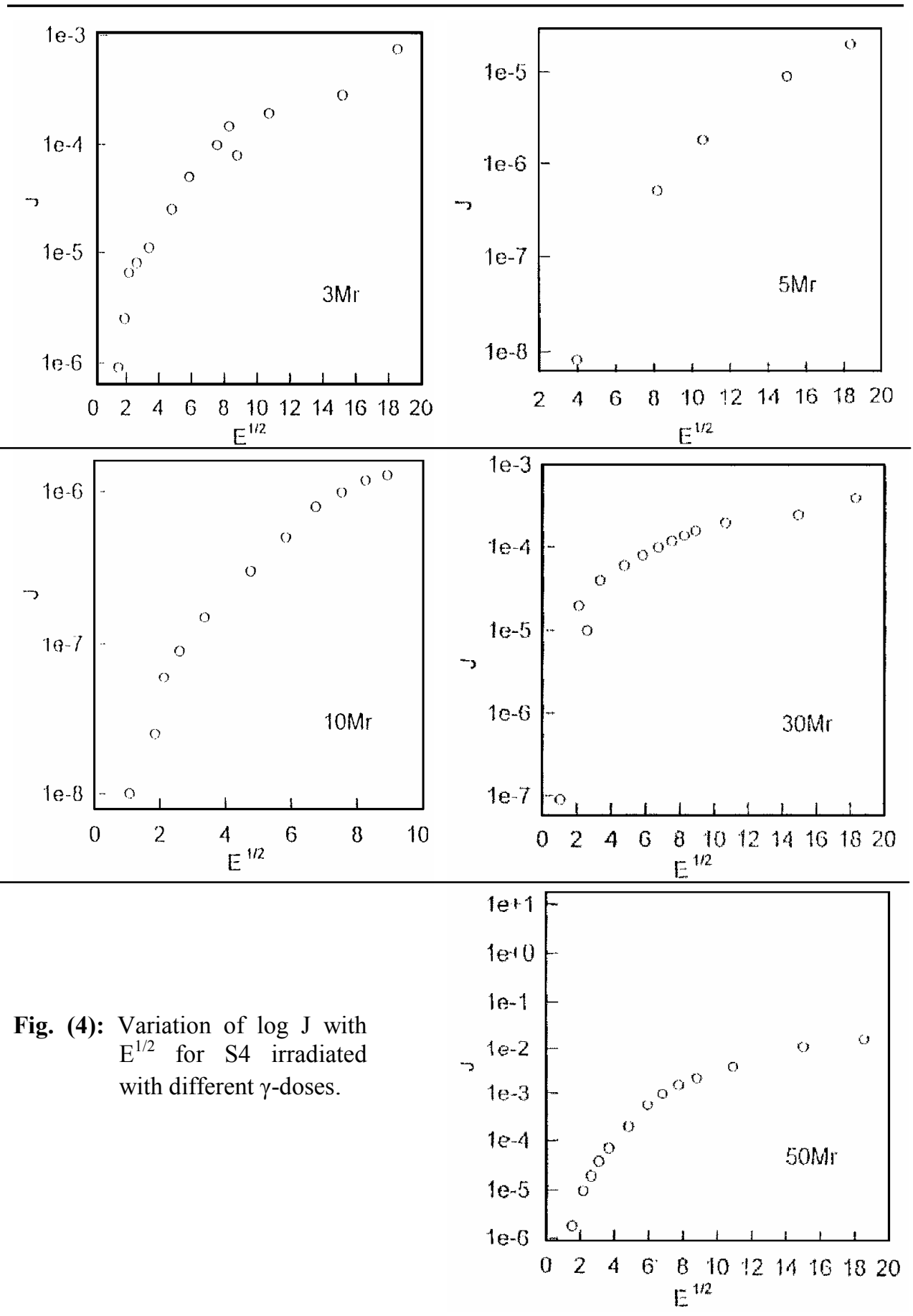




$$
\beta_{\mathrm{PF}}=2 \beta_{\mathrm{RS}}=2\left(\mathrm{e} / 4 \pi \varepsilon \varepsilon_{\mathrm{o}}\right)^{1 / 2}
$$

where $\varepsilon$ is the dielectric constant values of the samples that tabulated in Table (3) together with $\beta$ values. The experimental value of $\beta$ is in good agreement with $\beta_{\mathrm{PF}}$. It may therefore be concluded that the Poole-Frenkel type of conduction mechanism is dominant in these samples even with $\gamma$ - irradiation dose.

Table (3): The dielectric constant $\varepsilon$, and both the theortical and experimental $\beta$ values for: (A) unirradiated samples .

\begin{tabular}{|c|c|c|c|}
\hline Sample & $\begin{array}{c}\varepsilon \\
\text { measured }\end{array}$ & $\begin{array}{c}\beta_{\mathrm{PF}} \\
\text { Theoretical } \times 10^{-5}\end{array}$ & $\beta \exp \times 10^{-5}$ \\
\hline S1 & 14 & 2.03 & 2.0 \\
\hline S2 & 21 & 1.65 & 1.7 \\
\hline S3 & 13 & 2.1 & 2.2 \\
\hline S4 & 10.5 & 2.34 & 2.3 \\
\hline S5 & 20.0 & 1.69 & 1.6 \\
\hline S6 & 19.0 & 1.74 & 2.0 \\
\hline
\end{tabular}

(B) For sample $\mathrm{S} 4$ at different $\gamma$ - irradiation dose.

\begin{tabular}{|c|c|c|c|}
\hline $\begin{array}{c}\gamma \text {-dose } \\
\text { Mrad }\end{array}$ & $\begin{array}{c}\varepsilon \\
\text { measured }\end{array}$ & $\begin{array}{c}\beta_{\mathbf{P F}} \\
\text { Theoretical } \times 10^{-5}\end{array}$ & $\beta \exp \times 10^{-5}$ \\
\hline 3 & 10.5 & 2.34 & 2.3 \\
\hline 5 & 14.7 & 2.0 & 1.98 \\
\hline 10 & 7.7 & 2.75 & 2.73 \\
\hline 30 & 24.9 & 1.52 & 1.3 \\
\hline 50 & 25.0 & 1.5 & 1.16 \\
\hline
\end{tabular}

The effect of gamma rays on the electrical conductivity of the investigated compounds is calculated with respect to six different doses 0,30 , 50, 100, 300 and $500 \mathrm{kGy}$ at room temperature. From Fig. (5a,b), it is clear that at room temperature, the value of $\sigma$ for unloaded SBR $\left(S_{1}\right)$, initially, increased to approximately $10^{10}$ times its value upon irradiation by $30 \mathrm{kGy} \gamma$ - dose and then decreased till $<100 \mathrm{kGy} \gamma-$ dose. On the other hand,the values of $\sigma$ for SBR loaded with mixed ratio of $\mathrm{Cu}$ and $\mathrm{Fe}$ fine powder showed an undulatory behavior with $\gamma$ - dose. It may be presumed that the action of $\gamma$ - rays on polymer, results in excitation of its molecules and creation of free electrons and ions [4]. Moreover, the filler particles were ionized by the action of gamma ray. These electrons and ions migrate through the polymer network till they are trapped leaving deficient regions. These induced electronic and ionic configurations cause the changes in the electrical properties of polymeric materials. 

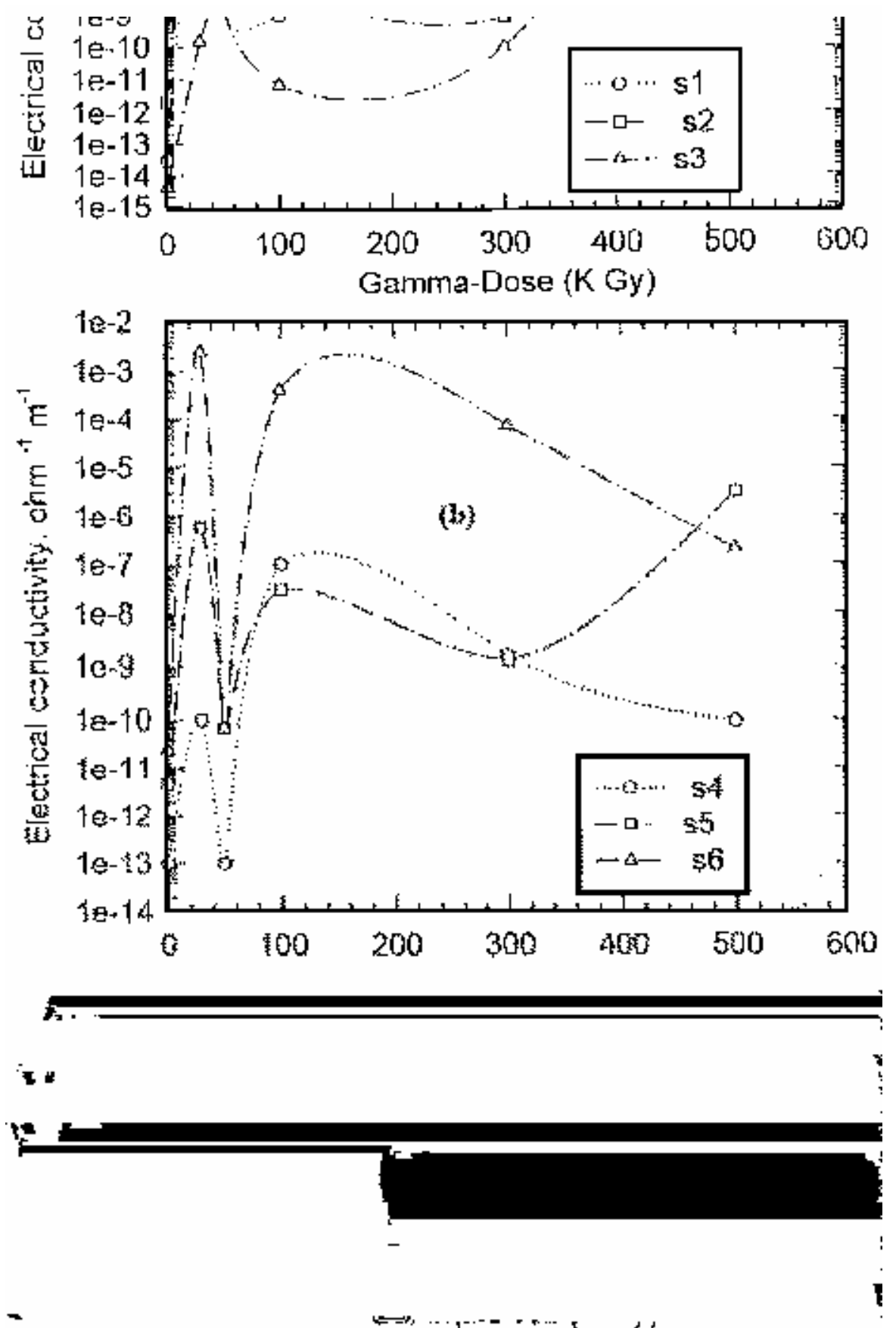

Fig. $(\mathbf{5 a}, \mathbf{b})$ : Variation of the d.c. electrical conductivity of SBR loaded with metallic filler ratios with $\gamma$-dose. 
At a relatively high irradiation dose $>300 \mathrm{kGy}$ there is an appreciable increase in $\sigma$ (for S2 and S3) as a result of the increased crosslinking affected by the metal powder content. The two processes of degradation and crosslinking alternatively occur for the loaded SBR samples. The detected decreasing behaviour in $\sigma_{\mathrm{dc}}$ up to $100 \mathrm{kGy}$ (S2 and S3) and up to $50 \mathrm{kGy}$ (S4, S5 and S6) is mainly due to the dissociation of C-C and C-H bonds that leads to degradation process by which the separation between metal fine particles increases. For a dose greater than $300 \mathrm{kGy}$, the crosslinking process takes place leading to a close contact between metal fine powder which in turn causes an increase in $\sigma_{\mathrm{dc}}$ as it was detected for samples $\mathrm{S}_{2}, \mathrm{~S}_{3}$ and $\mathrm{S}_{5}$. Meanwhile, the de-agglomeration of $\mathrm{Cu}$ metal powder aggregation takes place at $100 \mathrm{kGy}$, for samples $\mathrm{S}_{4}$ and $\mathrm{S}_{6}$ which contain mixed ratio 50:50 and 10:90 of Cu:Fe metal powders, respectively.

\subsection{Thermal properties of irradiated SBR loaded samples}

As a rule, crosslinking and degradation occur simultaneously. However, the ratio of their rates depends on the chemical structure of the polymer, its physical state and the irradiation conditions [23].

Figure (6a-c) represent the dependence of the thermal properties (thermal diffusivity, a, specific heat $\mathrm{C}_{\mathrm{p}}$ and thermal conductivity $\lambda$ ) on the filler content $(\mathrm{Cu}$ and $\mathrm{Fe})$ at different $\gamma$ - dose. The addition of filler powder ( $\mathrm{Fe}$ and/or $\mathrm{Cu}$ ) at different gamma doses (10-300 kGy), decreases both $\lambda$ and $\mathrm{C}$ as shown in Fig. $(6 \mathrm{~b}, \mathrm{c})$ owing to the increasing of phonon scattering. This effect could be due to both the liberation of scattered electrons from the metal atoms and/or the increased crosslinking density upon irradiation. This in turn decreases the transmittance of the thermal vibrations owing to the initially decreased distance between macromolecular lattice. Fig. (6a) represents the filler dependence of the thermal diffusivity of SBR composites at different $\gamma$ doses. The general features of these trends could be summarized as follows:

- Thermal diffusivity, a, decreases with increasing $\gamma$ - dose (in the dose range 0 $-300 \mathrm{kGy}$ ) for sample loaded with $\mathrm{Fe} \geq 30 \mathrm{phr}$.

- Thermal diffusivity, a, has a descending behavior with the filler ratio in the SBR composites at (30 -70) kGy $\gamma$ - dose.

It might be concluded that the addition of $\mathrm{Fe}$ and /or $\mathrm{Cu}$ metal powders do not contribute well to the thermal diffusivity values and in addition, it lowered both $\lambda$ and $\mathrm{C}_{\mathrm{p}}$ for these SBR composites in the cocentration range (0-50 phr). 

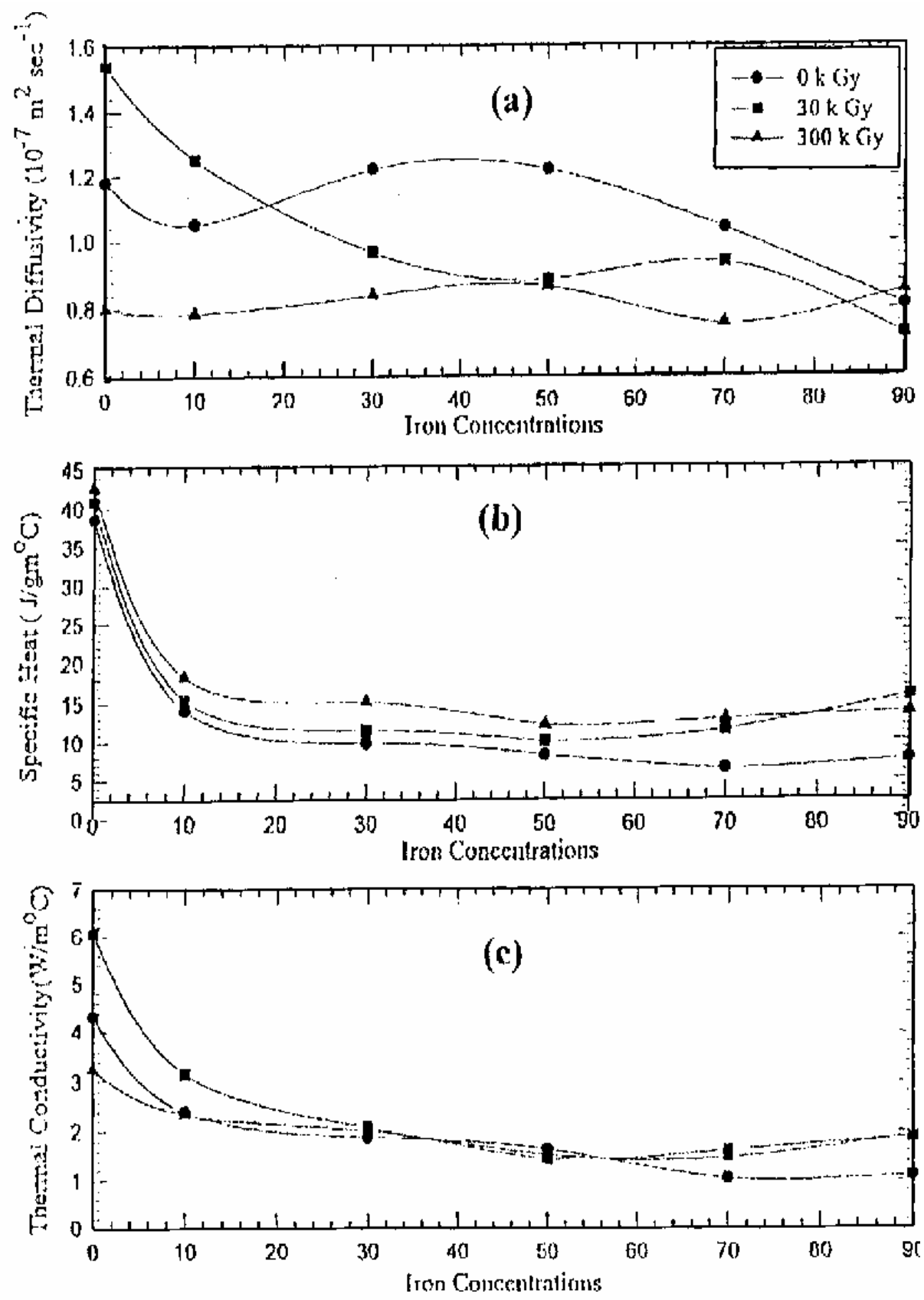

Fig.(6a,b,c): The dependence of (a) thermal diffusivity a,

(b) specific heat $\mathrm{Cp}$ and (c) thermal conductivity $\lambda$ on the metallic filler ratios in samples irradiated with different $\gamma$-doses 


\section{References:}

1. H.H. Hassan, E.M. Abdel-Bary, M.K. El-Mansy and H.A. Khodair Appl. Phys. Commu. 9(4), 281 (1990).

2. L.H.Sperling ,Introduction To Physical Polymer Science, John Wiley \&Sons, New York (1992).

3. T.A.Skotheim, E. "Handbook of Conducting Polymers", Marcel Dekker, Inc. New York, 351 (1986).

4. Charles A. Harper, Modern Plastics Handbook, McGraw Hill, New York (1999).

5. H.H.Hassan and M.K.El-Mansy, Gummi, Asbest. Kunststoff, 36(5), 204 (1983)

6. M. Amin, H.H. Hassan and G.M. Nasr, J. Polym. Sci, 21, 3353 (1983).

7. R.O. Ebewele, "Polymer Science and Technology", CRC Press, London, (2000).

8. M. Krumova, D. Lopez, R. Benavente, C. Mijangos and J.M.Perena, J. Polym, 41, 9265 (2000).

9. Z.N. Tarssova, M. Ya. Kaptunov, B.A. Dogadkin, V.I. Karpov and A.Kh. Brger, Kauchuki rezina, 17(5), 14 (1958).

10. P.S. Dale, J.S. Skutnik, J. Bolesh and G.G.A. Boem, J. Polym. Sci., 12(5), 925 (1974).

11. B. Crist, J. Polym. Phys. Ed., 28, 164 (1990).

12. F.C. Schilling, A.E. Tonelli and A.L. Cholli, J. Polym. Sci., 30, 91 (1992).

13. M.A. Fadel, Radiation Effects, 31, 299, (1977).

14. B. Khaif, Polymer Material Science, ed.j.Schnftz. Prentice- Hall Inc., New York, (1974).

15. A. Elwy, M.M. Badawy and G.M. Nasr., J. Polym. Degradation and Stability, 53, 289 (1996).

16. S.E. Gwaily, G.M.Nasr, M.M. Badawy and H.H. Hassan, Polym. Degrad. and Stab. 47, 391-395 (1995).

17. S. Radhakrishnan and D.R. Saini, J. Mat. Sci., 26, 5950 (1991).

18. J.M.Funt, Rubber Word, 1935, 21 (1987).

19. D.R. Prris, L.C. Burton and M.G. Siswanto, Rubber. Chem. Technol., 60, 705 (1987).

20. A.R.Blythe, "Electrical Properties of Polymers" Cambridge Univ. Press, Cambridge, London, New York, P.94 (1979)

21. P.C. Mehendru, N.L.Pathak, K.Jain and P. Mahendru, phys. stat. sol. (a) 42, 403 (1977).

22. K.V. Satyana, U.V. Subba Rao and V.V.R. Narasimha, J. Mat. Sci. Letter, 9, 3 (1990).

23. R.J. Woods and A.K. Pikaev. "Applied Radiation Chemistry: Radiation Processing", J. wiely Pub., New York, 343 (1994). 